
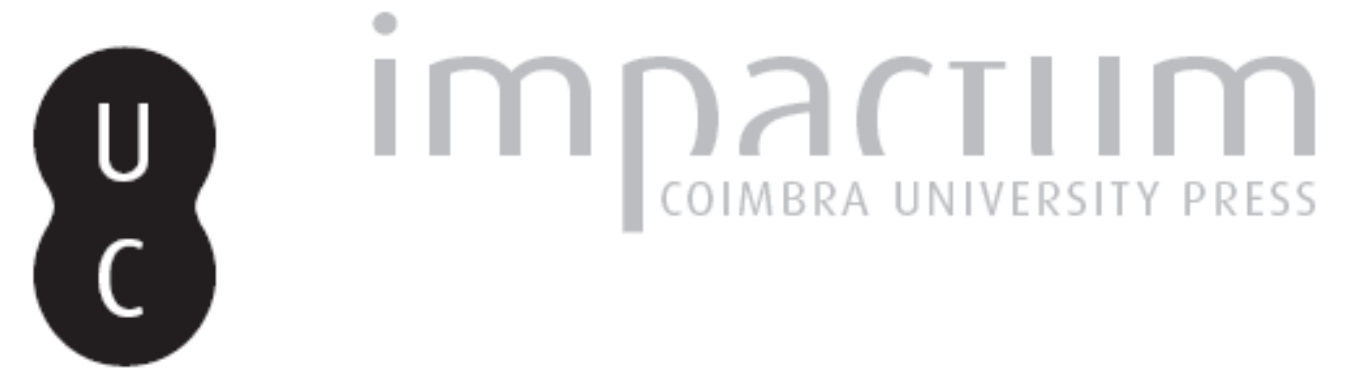

\title{
Sagrado \& Radical: La Poesía de Bob Cobbing
}

\section{Autor(es): $\quad$ Alfonso García, Alethia}

Publicado por: Centro de Literatura Portuguesa; Imprensa da Universidade de Coimbra

URL persistente:

URI:http://hdl.handle.net/10316.2/43615

DOI:

DOI:https://doi.org/10.14195/2182-8830_5-1_2

Accessed : $\quad$ 26-Apr-2023 09:57:56

A navegação consulta e descarregamento dos títulos inseridos nas Bibliotecas Digitais UC Digitalis, UC Pombalina e UC Impactum, pressupõem a aceitação plena e sem reservas dos Termos e Condições de Uso destas Bibliotecas Digitais, disponíveis em https://digitalis.uc.pt/pt-pt/termos.

Conforme exposto nos referidos Termos e Condições de Uso, o descarregamento de títulos de acesso restrito requer uma licença válida de autorização devendo o utilizador aceder ao(s) documento(s) a partir de um endereço de IP da instituição detentora da supramencionada licença.

Ao utilizador é apenas permitido o descarregamento para uso pessoal, pelo que o emprego do(s) título(s) descarregado(s) para outro fim, designadamente comercial, carece de autorização do respetivo autor ou editor da obra.

Na medida em que todas as obras da UC Digitalis se encontram protegidas pelo Código do Direito de Autor e Direitos Conexos e demais legislação aplicável, toda a cópia, parcial ou total, deste documento, nos casos em que é legalmente admitida, deverá conter ou fazer-se acompanhar por este aviso.

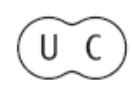




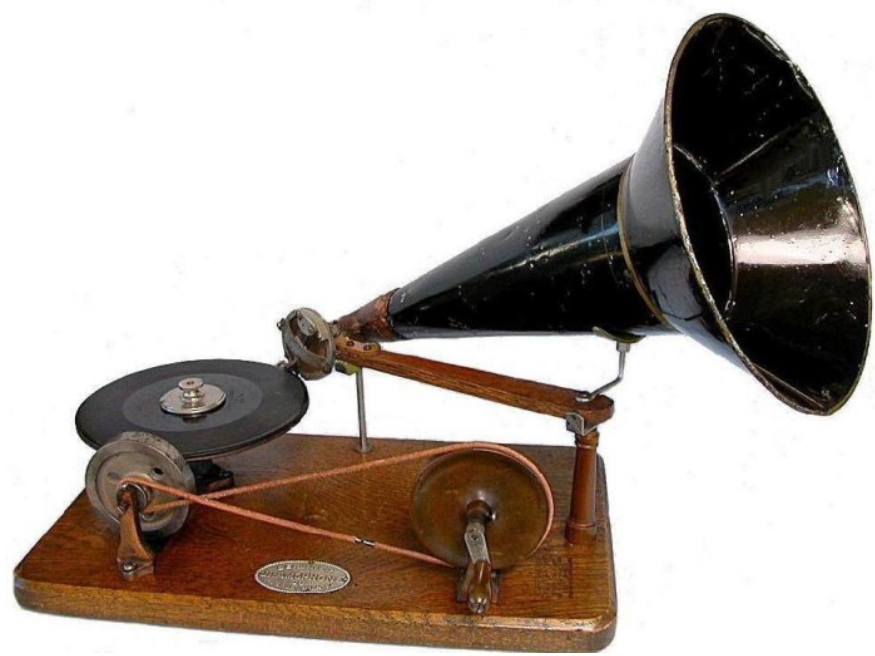

ช2

త్ర

త్ర్త్ర

(⿻)

घ)

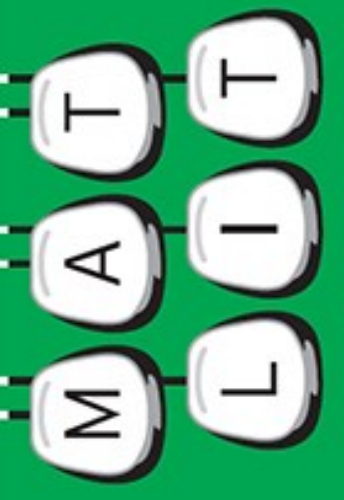

Vol. 5.1 (2017)

ISSN 2182-8830

'Vox Media: O Som na Literatura'

Osvaldo Manuel Silvestre e

Felipe Cussen (orgs.) 


\section{Sagrado \& Radical: La Poesía de Bob Cobbing AleTHIA AlFONSO GARCÍA

\author{
Universidad Iberoamericana Ciudad de México
}

\section{Resúmen}

El artículo analiza "The Sacred Mushroom" de Bob Cobbing (1920-2002), a partir de nociones de materialidad del lenguaje. En el breve recorrido por la poética escrita y sonora de Cobbing, se notarán las consecuencias de su práctica para el lectoraudiencia. Palabras clave: materialidad del lenguaje; Bob Cobbing; poesía sonora; meta-ética; estética.

\section{Abstract}

The current article analyses "The Sacred Mushroom" by Bob Cobbing (1920-2002), using notions of materiality of language. Throughout the brief analysis of Cobbing's sound and written poetics, consequences of his practice for the reader-audience will be pointed out. Keywords: materiality of language; Bob Cobbing; sound poetry; metaethics; aesthetics.

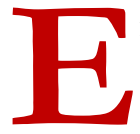

xisten dos maneras opuestas que he detectado hasta ahora en la caracterización de la materialidad del lenguaje. Por un lado, la versión de la fisicalidad y búsqueda formal: cuando por materialidad se entiende el lenguaje del texto impreso o enunciado y por lo tanto, se observa la forma de impresión, el tipo de tinta, la fuente empleada, las imágenes dentro del texto, el tipo de papel, los espacios en blanco, las versiones digitales, las versiones sonoras o audiovisuales, el performance, la ejecución (individual o colectiva). Por otro lado, la materialidad también se entiende como las condiciones materiales de producción, del libro, del poemario y más interesantemente de la enunciación. En ese último sentido es relevante para este artículo el nominalismo que David Bleich (2013) emplea para denunciar el uso jerarquizado que se hace del lenguaje académico en las universidades. Su importancia para el artículo estriba en que ciertos rasgos del nominalismo de Bleich ayudan a entender las consecuencias ético-estéticas del performance sonoro en la poesía contemporánea. Las características que Bleich considera relevantes sobre el lenguaje y que retomo son: entender el lenguaje como práctica de habla y sobre todo como un fenómeno que depende de la semejanza familiar y del performance. Ambos rasgos se detallan a continuación. 


\section{Definiciones: nominalismo y semejanza familiar}

David Bleich marca cuatro características del lenguaje, a partir de su entendimiento de Ludwig Wittgenstein. Por principio de cuentas el lenguaje no parte de un estándar ni se considera universal y único para una cultura o país. Por el contrario, el lenguaje es una práctica de habla, que por lo mismo se parcela en comunidades. Práctica de habla se entiende como un ejercicio continuo que logra comunicarnos más por las relaciones semióticas comunes (e incluso de resemiotización, es decir, la resignificación que ciertas comunidades le otorgan a ciertos vocablos) que por el aprendizaje de las reglas gramaticales. Generan prácticas discursivas, una vez que se encuentran con la política, y a su vez gestan formas de enunciar conocimiento.

Además de práctica de habla, el lenguaje es tanto un performance (performance es sustantivo masculino en español mexicano) como un juego. En términos Wittgenstein-Bleichianos es un Sprachspiel: en cada práctica de lenguaje hay una interrelación-tomada más o menos seriamente según el contexto-que espera reciprocidad y una ejecución o respuesta que parece ensayada porque sigue convenciones, esto es la asunción de un rol para que tal interrelación sea posible. El ejemplo más simple es la convención de decir "buenos días" si alguien enuncia el mismo vocablo frente a nosotros.

Bleich también menciona que el lenguaje es una forma viva que describe y no explica. Aunque estas características son relevantes para el estudio de las prácticas de habla en la academia, me remito a referir el capítulo tres del libro de Bleich para mayor ahondamiento. Más importante para este artículo resulta la característica denominada Familieähnlichkeit o semejanza familiar. Este rasgo evita que los interlocutores caigamos en la imposibilidad de comunicación. Porque aunque cada hablante creara su propio cúmulo de términos y expresiones, la familiaridad y relación cotidiana entre miembros de una misma comunidad permitirían tener descripciones comunes, incluso tropos comunes-siendo las sinécdoques las más comunes, por ejemplo cuando al recordar una anécdota, basta mencionar una frase para que los participantes en ella comiencen a reaccionar ante el recuerdo/enunciación. Queda patente entonces que es posible entablar interlocución y participar en el rol de hablante durante un acto de habla, sin que esto indique voluntad por estandarizar el lenguaje. El siguiente punto será entender la poesía sonora como acto de habla y las consecuencias de esto en su análisis y crítica.

\section{De la práctica de habla a la materialidad (o fisicalidad) de la poesía}

Reconocer las características de juego y performance, además de la semejanza familiar en las prácticas de habla plantea un reto interesante para la crítica de poesía sonora. Porque permite ver la práctica poética como una posibilidad de práctica de habla. Alejaría a la crítica poética de la materialidad, vista ex- 
clusivamente como recuento del uso del espacio (impreso y del performance) y uso de la voz (en la enunciación grabada y accesible a nosotros por YouTube). O bien, le otorgaría al análisis mencionado un lugar secundario, para dejar el protagonismo al entendimiento estético y a la toma de postura (cuasi política) que realiza Cobbing en The Sacred Mushroom. Todo parece factible, pero ¿a qué me refiero con una posibilidad peculiar del acto de habla?

Acordemos que en tanto parte de las prácticas de habla, cualquier poema puede ser un ejemplo de tal práctica. Para distinguirlo diría que es peculiar porque a las características de Bleich enunciadas brevemente, se le agrega un componente sui generis (aunque común en toda la poesía, sea vanguardista, experimental, sonora o neoclásica, como la identifica Eric Mottram en Towards Design in Poetry (2004)): esto es un uso estético del lenguaje. Esto significa llanamente hacer que ese hipotético y genérico poema tenga como consecuencia la percepción de algo por parte de quien lee, escucha u observa la ejecución del mismo. Hasta aquí las semejanzas con cualquier clase de poema. Sucede además que la práctica poética de Cobbing se separa de la poesía más convencional porque las referencias impresas (no siempre escritas en grafías legibles), no son necesariamente la transcripción a pie juntillas de lo que sucede en la ejecución sonora. En pocas palabras: lo que se ve o lee en un poema, no es lo que se escucha y ve en el escenario. Y cada acto de enunciación por parte de Cobbing tendría una variante de la ejecución anterior.

Eric Mottram explicaba desde el primer frente de experiencia en el British Poetry Revival la diferencia entre texto impreso y ejecución en Towards Design in Poetry. Mottram asumía que el texto impreso era una partitura que se interpretaba libremente al momento de enunciar o ejecutar el performance de la obra en cuestión. Mottram describía por lo mismo la escritura y la ejecución de un poema como si se tratase de diseño: "[and] design in many cases is completed by the performer: publication is not complete in the "text" (11). Esto realzaría la característica de semejanza familiar porque la constante acumulación de lecturas de poesía entablaría la semiótica común, que permitiría al espectador u oyente no desesperar y tener una experiencia estética. Entender la parte de diseño en la poesía entronca con la noción contemporánea de poesía sonora.

Mottram también acepta que debido "a continual mediation on the possibilities of connection... the work is subjected to constant changes, speculation, rejections, reformation and pattern grows through a series of physical modes" (2004:18). Mottram cita Colin Jones en el libro Systems, y emplea la analogía del poema como sistema complejo para ayudarnos a comprender, la (entonces, en los setenta, nueva) forma de hacer y ejecutar poemas: vista como diseño de sistemas complejos, la poesía apela a crear nuevas mediaciones entre el emisor y el receptor. Tales mediaciones dentro de una posibilidad de conexiones, como bien explica Mottram, hacen que el resultado de la experiencia poética sea volátil: está sujeta a cambios (ninguna enunciación o ejecución de poesía sería idéntica), a especulaciones y rechazo (cuando la 
experiencia poética no comparte la semejanza familiar del receptor o viceversa), a reformas y patrones que crecen y se modifican (cuando el ejecutante que puede ser el poeta u otra persona asume que debe modificar la forma de ejecutar o leer porque no percibe la conexión que le gustaría por parte del espectador).

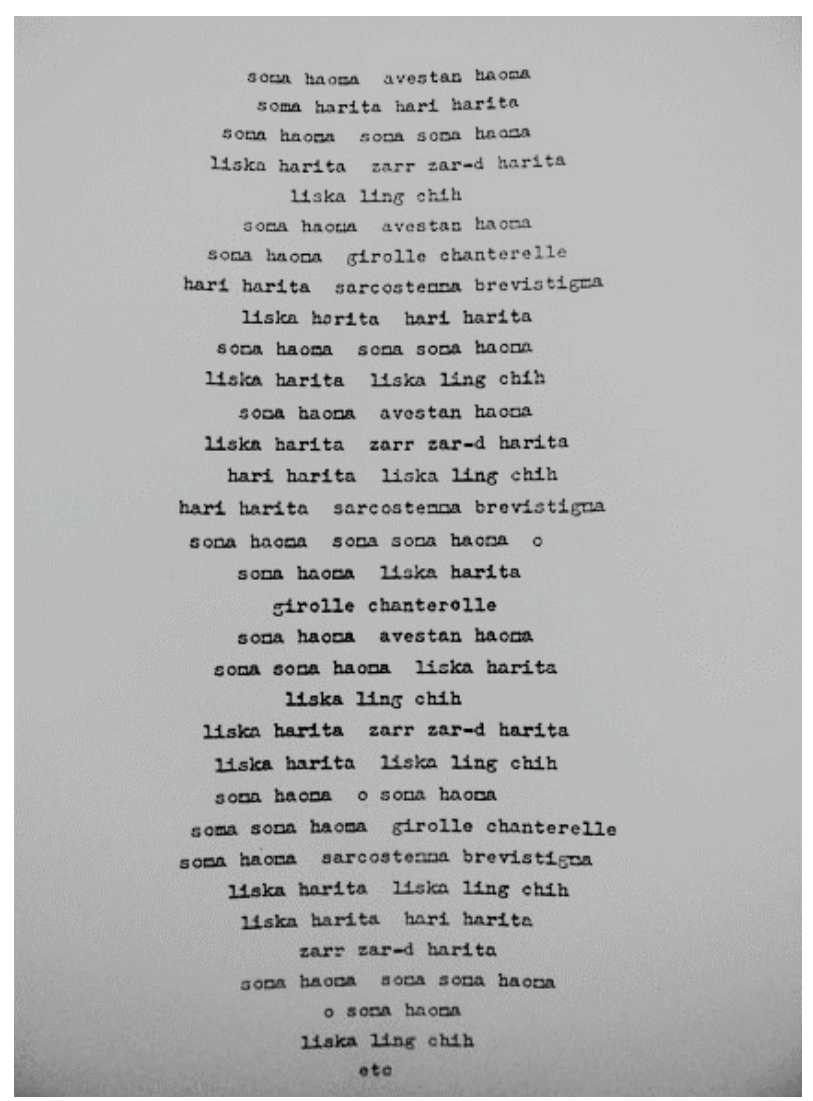

Fig. 1. Bob Cobbing. "Soma Haoma." The Sacred Mushroom 1980.

Londres. British Library.

Hasta este punto, dos de las aproximaciones, la una teórica (Bleich), la otra crítica (Mottram), convergen para explicar que la poesía sonora—al menos aquella de la segunda ola de vanguardia a la fecha-es una práctica de habla donde la arbitrariedad de su enunciación se entiende como un llamado a la semejanza familiar. Esta es la condición para que la experiencia estética tenga lugar. Es una práctica, enfatizaría Mottram, donde los patrones acordados de entendimiento sobrepasan el lenguaje escrito: "the sign is fast replacing the word... Semantics is giving way to semiotics" (2004: 38). Por lo tanto, en lugar de fundamentar su análisis en la semántica y la interpretación hermenéutica, lo hacen en la semiótica. La unidad de sentido, el signo, deviene cosa escrita, impresa, enunciada, actuada, imagen, y también movimiento 
corporal, funciones corporales, modos de usar la voz, los componentes en un escenario o en una mesa. En suma signo es algo que contribuye a la ejecución del sentido de un poema pero no depende de reglas gramaticales-y es volátil, por lo tanto cambiante. Por ejemplo: colocar fotografías de piedras para ejecutar textos sonoros (como el performance de Paula Claire en 1974, referido en Towards Design...) o reunir cuatro personas para gritar a todo pulmón en canon (basta buscar en el navegador el video de los Four Horsemen, un grupo de poesía sonora canadiense activo desde los setenta). Y por supuesto otro ejemplo es el poema que da nombre al artículo: The Sacred Mushroom de Bob Cobbing.

El poema está conformado por 6 cartulinas realizadas en 1980 e impresas en 2002 por Veer Books (Londres) bajo el título The Sacred Mushroom. (Figura 1). Una de las cartulinas sin título se compone de 33 líneas, con términos que se repiten. A menos que el lector entienda un poco de culturas no occidentales o tenga un navegador a mano, será difícil comprender que las líneas se refieren en algunos casos a hongos silvestres, en otros a bebidas rituales, en otros a textos védicos y en otros más a textos zoroastristas. La posible anécdota detrás es el ritual de iniciación védico o zoroastrista donde los involucrados (humanos usualmente) beben algo (soma o haoma) que les da cualidades de dioses. Sin ahondar mucho en los textos sagrados, basta saber que algunos refieren inmortalidad y otros a la luz y fuerza de los dioses. El componente material (sin consideraciones de teoría crítica todavía) es peculiar por las cartulinas en que están hechos y por la grafía que claramente alude al uso de máquinas de escribir para darle forma al poema. El manejo de sonidos es armónico en la impresión, porque el uso de las mismas palabrasno siempre en el mismo orden-crea una sensación de tener acordes (entendidos como sonidos simultáneos o bien seguidos uno de otro) que situados en diferentes posiciones del poema crean familiaridad con el sonido que emiten. Sería lo opuesto a la monotonía, como sucede con las canciones comercializadas masivamente. Esta fisicalidad habla, en retrospectiva, de algunos elementos de ruptura con la convención poética. La impresión es artesanal por el uso de papel y de las fuentes, el tema sale de las lindes occidentales y urbanas_temas ya comunes para 1970_. Hasta aquí el breve análisis sobre la materialidad (ajena a la política) del poema.

\section{La materialidad y el discurso detrás de la poesía sonora de Cobbing}

Por peculiar que se vea o escuche, la poesía no es sino un producto de su tiempo. La poesía de Cobbing es denominada radical y definida en cuanto a su pérdida por Mottram (quien a su vez emplea un fragmento de Herbert Marcuse en Counterrevolution and Revolt impreso en 1972): 
Radical literature which speaks in formless semi-spontaneity and directness loses with the aesthetic form the political content ... with (the reemergence of the form) we find a new expression of the inherently subversive equalities of aesthetic dimension, especially beauty as the sensuous appearance of the idea of freedom. (2004: 28)

Esto es: la forma cuidada aleja a la práctica poética del gesto radical—y por lo tanto aleja a la misma práctica del contenido político implícito en un gesto radical. Por radicalidad Mottram, Cobbing y otros miembros de British Poetry Revival (BPR) entendían la revisión y cuestionamiento de las características fundamentales de la poesía, por ejemplo la univocidad que existía entre texto impreso y enunciación de este. Transmitir algo deja de ser escribir un mensaje en grafías legibles con rima y tropos, porque lo fundamental es entablar una relación entre el receptor del poema, el poema mismo y el emisor. Fieles a la influencia de los sesenta y setenta de la fenomenología, los BPR asumían como fundamental la relación entre sujetos y objetos. Primaba también la idea de distanciarse del lenguaje (convencional) para ser conscientes de este. Maggie O'Sullivan detalla en el homenaje a Cobbing (Pennsound 2007) que extrañarse del/frente al lenguaje, permitía a Cobbing adquirir fuerza porque abría la posibilidad de ser consciente de lenguaje y replantear la relación de este con los receptores y enunciantes "[there's] absolute strength to become aware [of language]" (O’Sullivan, 2007). La separación y desemejanza entre el texto impreso o texto base y el performance o ejecución sonora del poema refuerza la relevancia de esta relación por demás arbitraria. Para muestra, baste escuchar a Cobbing:

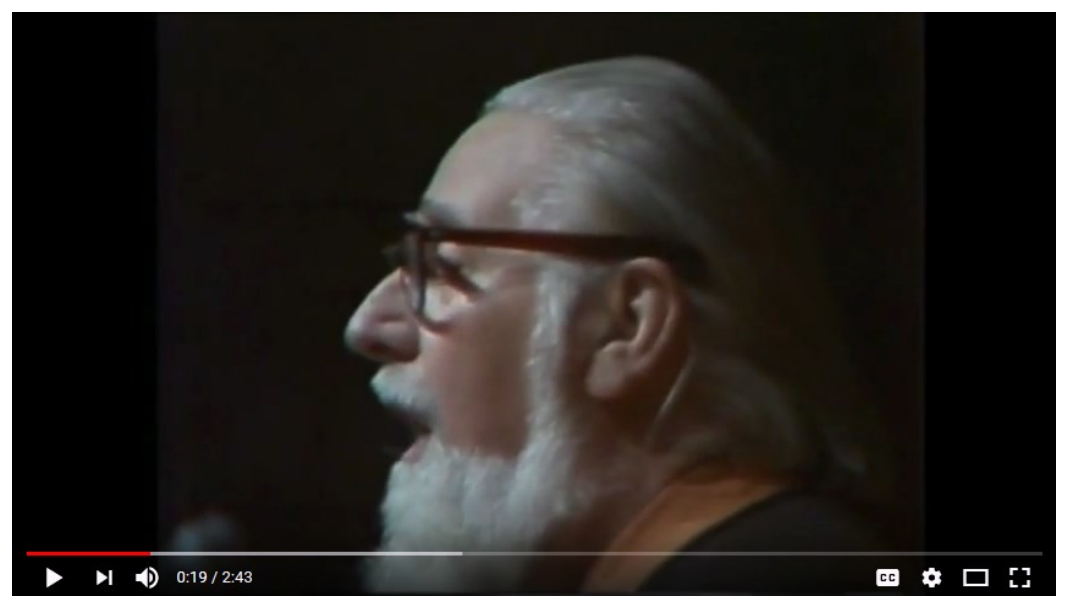

Media 1. Bob Cobbing. The Sacred Mushroom. YouTube. 2013.

Respecto a las consecuencias para el análisis y la crítica de la diferencia entre texto impreso y grabación sonora, Charles Bernstein 
enfatiza que "the audio text may be one more generally discounted destabilizing textual element, an element that undermines our ability to fix and present any single definitive, or even stable, text of the poem" (2006: 281). La cita de Bernstein refuerza la idea de arbitrariedad al presenciar la diferencia entre texto impreso y grabación. Va incluso más allá cuando intuye que pueden existir otras ejecuciones del mismo texto con otras variantes, y por lo tanto la creencia de la fijación y univocidad del texto impreso sería obsoleta. En la grabación que obtuve de manera gratuita en la red, se escucha la voz de Cobbing enunciar algunos elementos gráficos (palabras) presentes en el poema impreso, no en el mismo orden. Aunque estos elementos se repiten, la variación de Cobbing consiste en cantarlos con voz en registros diferentes: a veces el canto es abierto y en el tono cómodo para el intérprete, en otros momentos el casi trance de escuchar sonidos semejantes se transforma en sonidos guturales o gruñidos-similares al de culturas mongola y tibetana cuando interpretan cantos sagrados. La raíz sagrada, orientada a los cantos y libaciones de humanos que buscan el acercamiento con los dioses del poema impreso, no se traslada verbatim. Queda la posibilidad de hacer audible la experiencia de lo sagrado con la emulación de los modos de interpretar asiáticos. En este sentido, la interpretación registrada no trata de lo sagrado, sino que intenta encarnar la parte ritual e iniciática implícita en el consumo de hongos sagrados, en culturas no occidentales. ${ }^{1}$ Todavía más a favor de la poesía y de la actitud anticolonialista: esta grabación y esta temática entroncan con lo expresado por Marcel de Lima Santos, siguiendo a Jerome Rothenberg sobre poesía, contracultura y shamanismo. La etnopoética de Rothenberg evita las dicotomías de civilización vs. barbarie, porque nota que la poesía experimental de la época moderna se relaciona con algunas búsquedas y prácticas de grupos otrora considerados salvajes o no civilizados. La investigación de Rothenberg y de Lima Santos nota que "the issues present in the conceptual representations of ethnopoetics are indeed far ranging and, likewise those found in the representations of shamanism at large ..., resemble those of a human, rather than primitive, poetics" (de Lima Santos, 2013). La poesía sonora de Cobbing pone énfasis en la similitud entre las prácti-

\footnotetext{
${ }^{1}$ Ante de continuar, soy consciente del berenjenal colonialista que esta interpretación puede reflejar. Baste decir que la experimentación, el arte concreto y la búsqueda de vías no occidentales para entender, escribir e interpretar poesía llevaron a Cobbing a grabaciones como esta—lejos estaba de afanarse en fijar identidades culturales para propósitos colonialistas.
} 
cas poéticas occidentales del siglo XX y las prácticas poéticas no occidentales, mal llamadas exóticas o bárbaras. Aunque es de esperarse que a la vuelta del siglo XXI, tal dicotomía ya no sea tópico de debate, es de admirarse que el gesto poético y político de Cobbing sea similar a la etnopoética de Jerome Rothenberg y de Lima Santos, e incluso similar a los estudios de Walter Ong sobre oralidad y escritura. Para esta clase de poesía sonora, como para los estudios de Ong: la oralidad es vista como natural y la escritura como artificial, términos que si bien suenan anticuados constituyeron un parteaguas para los estudios literarios y lingüísticos de culturas consideradas ágrafas (2002).

Ahora bien, si las variantes en la enunciación son posibles, el texto impreso no es la única posibilidad de darle sentido al poema y la noción de lenguaje es la de una práctica de habla, el segundo gesto político se centra entonces en la comunidad que acoge el poema de Cobbing. Los lectores, la audiencia y los enunciantes del poema requieren no solo de la semejanza familiar que ya había mencionado. También se necesita admitir que la actividad del lector y del receptor de la grabación debe ser más activa. ¿En qué sentido o para qué? Para que el poema tenga sentido, los lectores, la audiencia y el emisor establecen un punto de partida común, la semejanza familiar: es decir, el reconocimiento de que el poema tiene una lógica propia sin que eso implique que todo el poema se entienda, sea legible o sea audible para un público que no creció escuchando a Cobbing y que no perteneció al BPR. La participación más activa, siguiendo al nominalismo, sería: (1) Notar la arbitrariedad implícita en esta práctica poética. (2) Aceptar la arbitrariedad y participar conscientemente en este juego de habla-esta característica Bleich la trata también, en el libro ya mencionado. (3) Lo anterior convierte la práctica de habla en un performance también, porque la respuesta es la ejecución (verbal o no) de la experiencia asimilada (el performance de Cobbing y su devenir familiar conforme avance el video, o conforme re-escuchamos y releemos). (4) Identificar las consecuencias de este ejercicio en la práctica poética-sea como receptor o como emisor. Cobbing, Mottram y parte del BPR tenían claro que la intención iba contra la asimilación simple del poema, como si se tratara de un bien de consumo. Es decir, The Sacred Mushroom apelaba a la experiencia irrepetible_que ciertamente fue después comercializada por las galerías y museos de arte, pero en ese entonces, era un búsqueda legítima de libertad creativa y libertad en la asimilación de tal experiencia. (5) Identificar o al menos cuestionar si esa arbitrariedad y consenso de sentido(s) se da en otras prácticas de ha- 
bla, por ejemplo en los discursos políticos o en la enseñanza de los derechos y obligaciones de un ciudadano.

La esperanza para un proyecto de izquierda-del cual no pocos miembros del BPR fueron adeptos_-sería que notar conscientemente la arbitrariedad misma en las relaciones entre emisores y receptores de las prácticas de habla cuestionaría los significados y consecuencias para la vida diaria de los ejemplos citados-por citar un comienzo del cambio. Lo cierto es que no deviene necesariamente en gesto político, es decir, no deviene una acción o petición de acción que cambie el rumbo de un gobierno. Lo que sí se logra sin embargo es un gesto cuestionador sobre la libertad de acción y pensamiento del ser humano, relacionada a las prácticas de habla (y discursivas en un siguiente plano de análisis) que permiten expresarse pero que también limi$\tan$.

He ahí el gesto que denomino ético, o concretamente metaético: porque intenta que el receptor (sea lector o audiencia) interrogue las bases de relaciones entre prácticas de habla y entre los discursos establecidos, fundamentadas en algunas de esas prácticas. La lección de Cobbing es sobre libertad: libertad para obedecer o para reaccionar contra aquellas reglas del juego que parezcan absurdas. La lección se funda en la capacidad para notar las reglas del juego metatextual, ese aceptar la arbitrariedad y aun así entrar en el juego-lo cual es una condición requerida para comprender el discurso detrás de los productos estéticos, culturales y de otras índoles. Se lee con una simplicidad exquisita, pero es crucial: la apuesta va por la capacidad humana. Contraria por ejemplo a la lógica consumista de comodificación de la vida-una lógica que prefiere ahorrarnos el esfuerzo de pensar o replantear las reglas del juego, los modos de vida o de experiencia estética-la apuesta de Cobbing va por la capacidad para cuestionar, para apelar, para entrar conscientemente en un juego de sentidos.

O'Sullivan añade en su participación en el homenaje a Cobbing un "[the poet] becomes the medium of the herd" (O'Sullivan, 2007). Lo devenir médium no es gratuito: ese es el gesto más radical de todos. La arbritrariedad ya comentada, la asunción de la semejanza familiar y aceptar las reglas de juego donde el recepto del poema se esfuerza un poco más que en las lecturas de poesía regulares otorgan al poeta un rol potencialmente similar al de shaman. Si bien en contextos sagrados, la noción de médium era un mediador con lo sagrado, en este ejemplo cercano a 1980, el poeta o emisor media entre el receptor y la experiencia poética, que puede devenir en experiencia estética si todas 
las condiciones para asumir el rol de receptor se cumplen (condiciones o pasos enumerados en los párrafos anteriores). El gesto estético sueña con convertirse en gesto político y logra definitivamente asumir un gesto (meta)ético: que sacude entonces no solo la noción de poesía y poesía sonora. También sacude al receptor de ésta, en tanto ente viviente que descubre o confirma una capacidad para cuestionar lo que tiene en frente-la poesía más tradicional para empezar, y las reglas de juego cotidiano para seguir. Cierro entonces con la intención, los gestos y con el parteaguas que significó poner en tela de duda la otrora inmediata relación entre texto y enunciación. Cambió no solo la manera de ejecutar poesía sonora, también ayudó a cuestionar a otros poetas y lectores. Quiénes entre los poetas que conocemos asumen a su audiencia y lectores como entes con habilidad para desarrollar semejanza familiar.

The Sacred Musbroom encarna su referencia primaria, de una manera no concluyente ni cerrada. Emplear el nominalismo y sus características (Bleich), al igual que el entendimiento contemporáneo o afín a Cobbing sobre la poesía y su radicalidad (Mottram, O’Sullivan; Bernstein, Rothenberg, de Lima Santos) permiten notar el gesto que transita la estética y culmina en (meta)ética. ¿Qué sigue después de esto? En el entendido de que la poesía y la literatura no son líneas de progreso sino que tiempos, espacios, poetas y poéticas tienen una relación constelar entre sí, quedan al menos dos aspectos donde ejercer esta nueva relación entre receptor, práctica poética y emisor o autor. (1) Otros poetas, en particular sería interesante saber qué (sobre)entienden por práctica poética y qué tan capaces consideran a su público o a los otros emisores o ejecutantes del poema. (2) Comprender cómo se mira o entiende ese gesto esético-ético ahora, 40 años después, cuando la comodificación de las artes parece haber absorbido procesos de producción y materialidades como los que Cobbing y compañía asumían anticomercializables. Ambos aspectos refuerzan una sola cuestión: la poesía sonora en The Sacred Mushroom es índice del gesto—casi esperanzadoralbergado en las expresiones posteriores a la primera vanguardia. La esperanza ya quizá no apunta al cambio político: se vuelve íntima-porque es posiblemente en la intimidad donde se gesten y acuñen los cambios más radicales. ${ }^{2}$ En este caso, la intimidad explorada atañe a la práctica poética.

\footnotetext{
${ }^{2}$ Para ahondar sobre el tema, véase André Gorz, Farewell to the Working Class: An Essay on Post-Industrial Socialism, Londres: Pluto Press, 1987.
} 


\section{Referencias}

BERNSTEIN, Charles (2006). "Making Audio Visible: The Lessons of Visual Language for the Textualization of Sound." Text 16: 277-289. http://www.jstor.org/stable/30227924

BLEICH, David (2013). The Materiality of Language: Gender, Politics, and the University. Bloomington: Indiana University Press. ProQuest ebrary. Web. 16 Julio 2016.

COBBING, Bob (1980). The Sacred Mushroom. Londres: Writers Forum. (2013). The Sacred Mushroom. Web. 31 Octubre 2016. https://www.youtube.com/watch?v=2VNW5wiFE4M

DE LIMA SANTOS, Marcel (17 Octubre 2013). "From The Poetics of Shamanism.” Jerome Rothenberg. Poems and Poetics. Blogspot. 25 Agosto 2017. http://poemsandpoetics.blogspot.mx/2013/10/marcel-de-limasantos-from-poetics-of.html

GORZ, Andre (1987). Farewell to the Working Class: An Essay on Post-Industrial Socialism. Londres: Pluto Press.

MOTTRAM, Eric (2004). Towards Design in Poetry. Londres: Veer.

O'SULLIVAN, Maggie (2007). "Roundtable discussion of the life and work of Bob Cobbing”. Bob Cobbing. Web. MP3. 11 Agosto 2017. https://media.sas.upenn.edu/pennsound/authors/Cobbing/SuddenlyEveryone-Began/OSullivan-Maggie_03_Discussion_SuddenlyEveryone-Began_KWH_10-11-07.mp3

ONG, Walter (2002). Orality and Literacy: The Technologizing of the World. $2^{\text {nd }}$ edition. Nueva York: Routledge.

(C) 2017 Alethia Alfonso García. Licensed under the Creative Commons Attribution-NoncommercialNo Derivative Works 4.0 International (CC BY-NC-ND 4.0). 